\title{
Maternal Systemic Lupus Erythematosus (SLE) High Risk for Preterm Delivery and Not for Long-Term Neurological Morbidity of the Offspring
}

\author{
Dora Davidov ${ }^{1}$, Eyal Sheiner ${ }^{1, *} \mathbb{C}$, Tamar Wainstock ${ }^{2}$, Shayna Miodownik ${ }^{1}$ and Gali Pariente ${ }^{1}$ \\ 1 Soroka University Medical Center, Department of Obstetrics and Gynecology, Ben-Gurion University of the \\ Negev, Beer-Sheva 84101, Israel; davidora88@gmail.com (D.D.); miodowni@post.bgu.ac.il (S.M.); \\ galipa@bgu.ac.il (G.P.) \\ 2 The Department of Public Health, Faculty of Health Sciences, Ben-Gurion University of the Negev, \\ Beer-Sheva 84101, Israel; wainstoc@post.bgu.ac.il \\ * Correspondence: sheiner@bgu.ac.il
}

\section{check for}

updates

Citation: Davidov, D.; Sheiner, E.; Wainstock, T.; Miodownik, S.;

Pariente, G. Maternal Systemic Lupus Erythematosus (SLE) High Risk for

Preterm Delivery and Not for

Long-Term Neurological Morbidity of the Offspring. J. Clin. Med. 2021, 10, 2952. https://doi.org/10.3390/ jcm10132952

Academic Editors: Emmanuel Andrès and Angelo Valerio Marzano

Received: 27 May 2021

Accepted: 29 June 2021

Published: 30 June 2021

Publisher's Note: MDPI stays neutral with regard to jurisdictional claims in published maps and institutional affiliations.

Copyright: (c) 2021 by the authors. Licensee MDPI, Basel, Switzerland. This article is an open access article distributed under the terms and conditions of the Creative Commons Attribution (CC BY) license (https:// creativecommons.org/licenses/by/ $4.0 /)$.
Abstract: Objective: Pregnancies of women with systemic lupus erythematosus (SLE) are associated with preterm delivery. As preterm delivery is associated with long-term neurological morbidity, we opted to evaluate the long-term neurologic outcomes of offspring born to mothers with SLE regardless of gestational age. Methods: Perinatal outcomes and long-term neurological disease of children of women with and without SLE during pregnancy were evaluated. Children of women with and without SLE were followed until 18 years of age for neurological diseases. Generalized estimating equation (GEE) models were used to assess perinatal outcomes. To compare cumulative neurological morbidity incidence a Kaplan-Meier survival curve was used, and a Cox proportional hazards model was used to control for confounders. Result: A total of 243,682 deliveries were included, of which $100(0.041 \%)$ were of women with SLE. Using a GEE model, maternal SLE was noted as an independent risk factor for preterm delivery. The cumulative incidence of long-term neurological disease was not found to be significantly higher when using the Kaplan Meier survival curves and maternal SLE was not found to be associated with long-term neurological disease of the offspring when a Cox model was used. Conclusion: Despite the association of SLE with preterm delivery, no difference in long-term neurological disease was found among children of women with or without SLE.

Keywords: systemic lupus erythematosus; preterm delivery; neurologic morbidity; offspring

\section{Introduction}

Systemic lupus erythematosus (SLE) is a chronic multisystemic autoimmune inflammatory disease with a wide range of clinical manifestations and it affects many organ systems [1]. While SLE mainly affects young women of childbearing age, the prevalence varies with the sex, age and ethnicity [1-3]. Treatment of SLE focuses on preventing and decreasing the severity and duration of flares, with the use of NSAIDs and antimalarial drugs for mild to moderate SLE and high dose corticosteroids for severe disease [4,5].

Antiphospholipid antibodies (aPL) are the main predictors of pregnancy complications, including miscarriage, fetal death, prematurity and preeclampsia, with lupus anticoagulant (LAC) being strongly associated with miscarriage and late fetal loss [6-8]. Furthermore, infants of mothers with SLE who were exposed to anti-Ro/SSA or antiLa/SSB antibodies during pregnancy have shown an increased risk for neonatal lupus syndrome, with its most serious manifestation being fetal heart block $[6,9,10]$.

Previous studies have examined immediate pregnancy outcomes of women with SLE. Recurrent pregnancy loss, preeclampsia, fetal growth restriction, preterm delivery, cesarean delivery and postpartum infections $[9,11,12]$ are some of the obstetrical complications shown to be correlated with SLE. 
Studies have pointed out an association of long-term neurological diseases in children of mothers with SLE, such as neurodevelopment impairment, learning and speech disorder, attention deficit hyperactivity disorder (ADHD) and autism spectrum disorders [13-15]. However these studies were limited by smaller cohorts.

Several factors have been suggested to affect neurodevelopment impairment among children born to mothers with SLE. This largely involves maternal autoantibodies that cross the placenta during fetal development which may result in learning disorders and dyslexia in offspring [16,17]. Additionally, prematurity was found to be linked to longterm neurological disease, such as cerebral palsy, particularly when chorioamnionitis was involved $[18,19]$.

Due to the link between maternal SLE and preterm delivery, we opted to investigate the association between maternal SLE and unfavorable perinatal outcome, and long term neurological disease of children born to mothers with SLE, regardless of gestational age.

\section{Materials and Methods}

This was a population-based retrospective cohort study that investigated perinatal results and long-term neurological diseases of children of mothers with and without SLE. The study compared various perinatal outcomes, such as perinatal mortality, caesarean delivery, recurrent pregnancy loss, hypertensive disorders, placental abruption and preterm delivery. A predefined set of ICD-9 codes (Table S1) was used as the basis for assessing the total neurological diseases of children of mothers with SLE up to the age of 18 years. These neurological diseases included psychiatric emotional disorders, movement disorders and total neurologic-related hospitalizations. Follow-up time was determined as time to an event (hospitalization with any neurological diagnosis). If any of the following occurred, follow-up ended: hospitalization resulting in death, first hospitalization with any neurological diagnosis or when the child reached 18 years of age. The study population included all children born to mothers with SLE during the years 1991-2014 at Soroka University Medical Center (SUMC), a tertiary hospital and the only medical center in the Negev, the southern region of the country, which covers $65 \%$ of the country's area (about 1.22 million people) [20]. Multifetal pregnancies and cases of congenital anomalies and chromosomal abnormalities were excluded from the study. Cases of perinatal mortality were excluded from the long-term analysis. Pregnancies prior or after the study period (1991-2014) were not included in the study. Hence some of the women in our study were multipara but only part of their pregnancies was included in our study. The institutional review board, in accordance with Helsinki declaration, approved the study (IRB number 0357-19-SOR).

Data were collected from two cross-linked and merged computerized databases, each based on mother and infant ID numbers: the perinatal database of the Obstetrics and Gynecology Department and the pediatric hospitalization database of SUMC (DemogICD9). The perinatal database contains maternal demographics, diseases and perinatal results documented immediately after delivery and anonymized before analysis. The pediatric hospitalization database contains demographic data and ICD-9 codes for all medical diagnoses recorded during any hospitalization at SUMC.

Among 100 women with SLE, data regarding disease activity, manifestations, presence of anti-Ro/La antibodies, anti dsDNA antibodies and anti-phospholipid syndrome (APS) antibodies were gathered by examining each women's file. The data were in $70 \%$ of the files (i.e., 30 women with SLE did not have information regarding disease activity or lack thereof during pregnancy). Severe SLE during pregnancy was defined as having active SLE during pregnancy (i.e., experiencing any SLE manifestation during pregnancy).

\section{Statistical Analysis}

Statistical analysis was executed utilizing SPSS 23rd edition. To compare background characteristics between the two study groups, univariable analysis was performed which included $t$-tests or Mann-Whitney $U$ tests for continuous variables and chi-square tests for categorical variables. Generalized estimating equation (GEE) models were used to compare 
perinatal outcomes, controlling for confounders and for maternal clusters. To compare the cumulative incidence of neurologic-related hospitalization in offspring of mothers with and without SLE a Kaplan-Meier survival curve was used. Finally, a Cox proportional hazards model was used to control for confounders. A $p$-value of $\leq 0.05$ was considered statistically significant. All analyses were two-sided.

Based on initial analysis, after excluding the offspring who did not meet the inclusion criteria, there were 242,246 offspring born to mothers without SLE, and 96 offspring born to mothers with SLE. The rate of pediatric neurological-associated hospitalizations, based on initial analysis, was $4.2 \%(n=4 \mathrm{x})$. This sample size has a power of $80 \%$ to detect an odds ratio of $5.8 \%$ between the study groups.

\section{Results}

\subsection{Maternal Characteristics and Perinatal Outcomes}

This study included 243,682 deliveries that met the inclusion criteria, of which 100 were from women with SLE $(0.041 \%)$. Information regarding disease activity during pregnancy was found in 70 women with SLE, of those, 20 women had flares during pregnancy. Disease activity manifested with arthritis (12 women), nephritis (9 women), dermatitis (8 women) and carditis (1 woman). Some women with flares had more than one clinical manifestation. While anti Ro/La antibodies were present in 3 women with flares during pregnancy, anti dsDNA antibodies were present in 10 women with SLE flares during pregnancy. Two women had prior APS antibodies. No information regarding prior organ damage was found in our population. Demographic and clinical characteristics of women with SLE are presented in Table 1.

Table 1. Demographic and clinical characteristics of mothers with and without SLE.

\begin{tabular}{|c|c|c|c|c|}
\hline Characteristic & $\begin{array}{l}\text { Mothers with SLE } \\
\qquad(n=100)\end{array}$ & $\begin{array}{l}\text { Mothers without SLE } \\
\qquad(n=243,582)\end{array}$ & $\begin{array}{c}\text { Odds Ratio }(95 \% \\
\text { Confidence Interval) }\end{array}$ & $p$-Value \\
\hline $\begin{array}{c}\text { Maternal age, } \\
\text { years (mean } \pm \text { SD) }\end{array}$ & $31.44 \pm 4.62$ & $28.16 \pm 5.8$ & - & 0.001 \\
\hline \multicolumn{5}{|l|}{ Gravidity (\%) } \\
\hline 1 & 18.0 & 19.7 & & \\
\hline $2-4$ & 23.0 & 47.8 & - & 0.585 \\
\hline$\geq 5$ & 59.0 & 32.5 & & \\
\hline \multicolumn{5}{|l|}{ Parity (\%) } \\
\hline 1 & 24.0 & 23.6 & & \\
\hline $2-4$ & 65.0 & 51.1 & - & 0.003 \\
\hline$\geq 5$ & 11.0 & 25.3 & & \\
\hline $\begin{array}{c}\text { Recurrent } \\
\text { pregnancy loss (\%) }\end{array}$ & 23.0 & 5.0 & $5.63(3.53-8.98)$ & $<0.001$ \\
\hline
\end{tabular}

Mothers with SLE were older and demonstrated higher rates of recurrent pregnancy loss. Perinatal outcomes of the study population are described in Table 2.

Higher rates of hypertensive disorders (13.0\% vs. $5.0 \%, p<0.001$ (caesarean delivery $(40.0 \%$ vs. $13.5 \%, p<0.001)$, preterm delivery $(28.0 \%$ vs. $6.9 \%, p<0.001)$ and perinatal mortality $(4.0 \%$ vs. $0.5 \%, p<0.001)$ were noted among women with SLE compared with women without SLE.

A GEE model that controlled for maternal age and disorders of hypertension demonstrated that maternal SLE was an independent risk factor for preterm delivery (adjusted OR $4.9,95 \%$ CI $3.20-7.80, p<0.001)$. Using another GEE model controlling for gestational age, the association between maternal SLE and perinatal mortality lost its significance (adjusted OR 2.4, 95\% CI 0.78-7.93, $p=0.123$, Table 3). 
Table 2. Perinatal outcomes of women with and without SLE.

\begin{tabular}{|c|c|c|c|c|c|}
\hline Characteristic & $\begin{array}{l}\text { Women with SLE } \\
\qquad(n=100) \\
(\%)\end{array}$ & $\begin{array}{l}\text { Women without } \\
\text { SLE } \\
\qquad \begin{array}{c}(n=243,582) \\
(\%)\end{array}\end{array}$ & Odds Ratio & $95 \% \mathrm{CI}$ & $p$-Value \\
\hline $\begin{array}{l}\text { Hypertensive } \\
\text { disorders }\end{array}$ & 13.0 & 5.0 & 2.8 & $1.57-5.06$ & $<0.001$ \\
\hline $\begin{array}{l}\text { Placental } \\
\text { abruption }\end{array}$ & 1.0 & 0.6 & 1.8 & $0.25-12.92$ & 0.552 \\
\hline $\begin{array}{l}\text { Preterm } \\
\text { delivery }\end{array}$ & 28.0 & 6.9 & 5.2 & $3.41-8.18$ & $<0.001$ \\
\hline $\begin{array}{c}\text { Caesarean } \\
\text { delivery }\end{array}$ & 40.0 & 13.5 & 4.2 & $2.85-6.35$ & $<0.001$ \\
\hline $\begin{array}{l}1 \text {-Min Apgar } \\
\text { score }<7\end{array}$ & 8.0 & 5.3 & 1.5 & $0.75-3.18$ & 0.258 \\
\hline $\begin{array}{c}\text { 5-Min Apgar } \\
\text { score }<7\end{array}$ & 3.0 & 2.3 & 1.3 & $0.42-4.22$ & 0.496 \\
\hline $\begin{array}{l}\text { Small for } \\
\text { gestational age } \\
\text { (SGA) }\end{array}$ & 7.0 & 4.6 & 1.5 & $0.71-3.34$ & 0.260 \\
\hline $\begin{array}{l}\text { Perinatal } \\
\text { mortality }\end{array}$ & 4.0 & 0.5 & 7.5 & $2.77-20.57$ & $<0.001$ \\
\hline
\end{tabular}

Table 3. GEE models for preterm delivery and perinatal mortality.

\begin{tabular}{cclccc}
\hline & Outcome & & Adjusted OR & 95\% CI & $p$-Value \\
\hline Model 1* & Preterm Delivery & $\begin{array}{l}\text { Maternal SLE (vs. } \\
\text { no maternal SLE) }\end{array}$ & 4.9 & $3.20-7.80$ & $<0.001$ \\
\hline Model 2** & Perinatal mortality & $\begin{array}{l}\text { Maternal SLE (vs. } \\
\text { no maternal SLE) }\end{array}$ & 2.4 & $0.78-7.39$ & 0.123
\end{tabular}

* Model 1 controls for maternal age and hypertensive disorders. ${ }^{* *}$ Model 2 controls for gestational age at birth.

\subsection{Long Term Neurological Morbidity of Offspring to Mothers with SLE}

After eliminating all cases of antepartum, intrapartum, and postpartum mortality, the population of the study included 242,342 children, among them 96 children of mothers with SLE. No significant difference was noted in long-term neurological disease between children to mothers with SLE and without SLE ( $4.2 \%$ vs. $3.1 \%, p=0.552$, Table 4$)$.

Table 4. Selected long-term neurological morbidity in offspring of women with and without SLE.

\begin{tabular}{cccc}
\hline Neurological Morbidity & $\begin{array}{c}\text { Maternal SLE } \\
(\boldsymbol{n}=\mathbf{9 6})\end{array}$ & $\begin{array}{c}\text { No maternal SLE } \\
(\boldsymbol{n}=\mathbf{2 4 2 , 2 4 6 )}\end{array}$ & $p$-Value \\
\hline Movement disorder $(\%)$ & 3.1 & 1.8 & 0.351 \\
\hline Psychiatric emotional disorder (\%) & 1.0 & 0.5 & 0.443 \\
\hline Total neurological hospitalizations (\%) & 4.2 & 3.1 & 0.552 \\
\hline
\end{tabular}

Severe SLE during pregnancy was defined as having flares of SLE manifestations during pregnancy. No significant difference was noted in long-term neurological disease between children to mothers with severe SLE during pregnancy compared with children to mothers with SLE with no manifestation of severity during pregnancy $(p=0.79)$

Similarly, no significantly higher cumulative incidence rate of long-term neurological morbidity in offspring of women with SLE was demonstrated by the Kaplan Meier survival curve (log-rank test $p=0.429$, Figure 1$)$. 


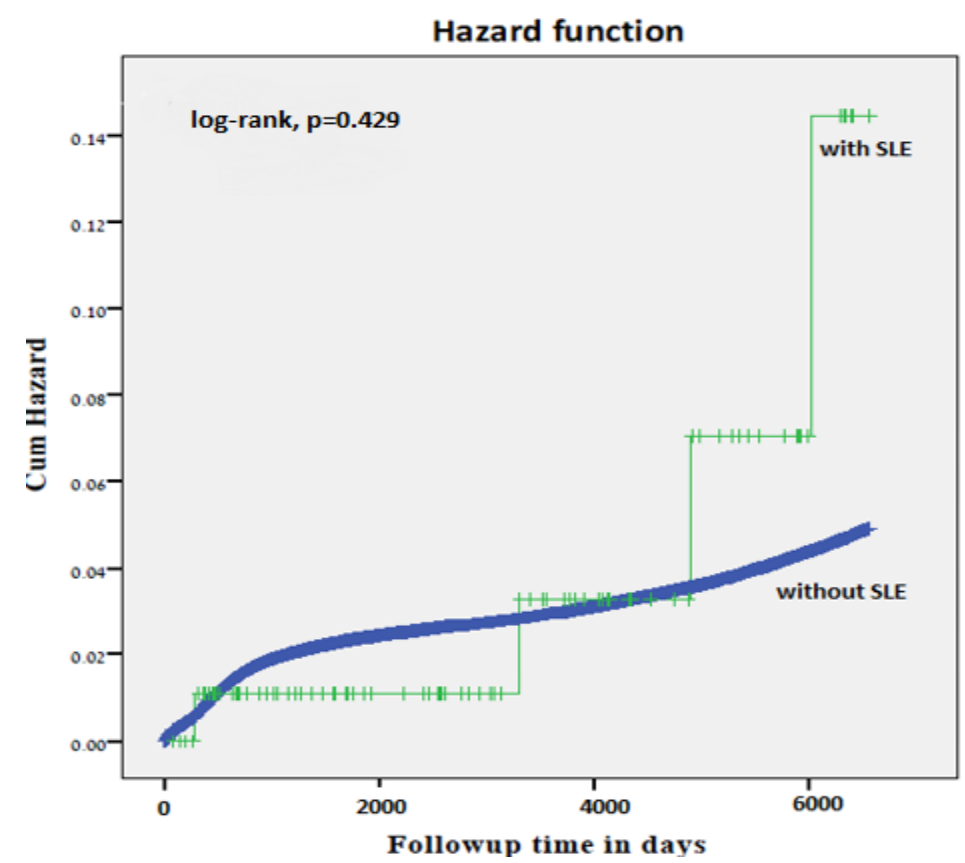

Figure 1. Kaplan-Meier survival curve demonstrating the cumulative incidence of neurologic-related hospitalizations in offspring of mothers with and without SLE (log-rank test, $p=0.429$ ).

A Cox proportional hazards model, controlling for gestational age and maternal age, demonstrated that being born to a mother with SLE was not found to be independently associated with long-term neurological disease of the offspring (adjusted HR 1.3, 95\% CI $0.51-3.62, p=0.539$, Table 5).

Table 5. Long-term neurological morbidity of children to women with SLE assessed by Cox proportional hazards model.

\begin{tabular}{cccc}
\hline & Adjusted HR & $\mathbf{9 5 \%}$ CI & $p$ Value \\
\hline Maternal SLE (vs. no maternal SLE) & 1.3 & $0.51-3.62$ & 0.539 \\
\hline Preterm delivery (<37 weeks) & 1.5 & $1.41-1.65$ & $<0.001$ \\
\hline Mother Age at Birth & 0.9 & $0.99-1.00$ & 0.268 \\
\hline
\end{tabular}

\section{Discussion}

The major finding of our study is that while maternal SLE was associated with a significantly higher risk for adverse perinatal outcomes such as preterm delivery, no significant difference in long-term neurological morbidity was found between offspring born to mothers with or without SLE.

\subsection{Perinatal Outcomes of Mothers with SLE}

The association between maternal SLE and adverse perinatal outcomes is well established. Studies of perinatal outcomes in women with SLE showed higher rates of recurrent pregnancy loss, preeclampsia, fetal growth restriction, cesarean delivery, postpartum infections and preterm delivery $[12,21]$.

Our study supports these findings, as hypertensive disorders, cesarean delivery rates, and recurrent pregnancy loss were higher among mothers with SLE compered with mothers without SLE. Preterm delivery rates were also higher among mothers with SLE. As preterm delivery has been demonstrated to be associated with maternal age [22], and hypertensive disorders [23,24], after using a GEE model controlling for maternal age and hypertensive disorders, maternal SLE was independently associated with preterm delivery. 


\subsection{Long Term Neurological Morbidity in Offspring Born to Mothers with SLE}

Contrary to our study, previous studies found an increased risk for long-term neurological morbidity in offspring of mothers with SLE, including learning disorders, ADHD and autism spectrum disorders [14,16,25,26]. Nalli, et al. [26] reported an increased risk of learning disorders in offspring to mothers positive for aPL antibodies. Nevertheless, a restricted sample size of only 10 children born to mothers with SLE, lack of a control group such as children born to mothers with systemic autoimmune diseases yet negative for aPL and self reported evaluations made it hard to interpret the study results. In their case-control study, Ross, et al. [16] studied 58 children born to mothers with SLE and 58 children born to healthy mothers. The authors demonstrated that sons of women with SLE, rather than daughters, were significantly more likely to have learning disabilities, and that the presence of anti-Ro and anti-La antibodies and disease activity were significantly related to a higher prevalence of learning disabilities in the offspring. As our study focused on neurological morbidity that is related to the health of the offspring, learning disabilities were not addressed in our study.

Prior studies have demonstrated the influence of maternal autoantibodies on several aspects of fetal development during pregnancy, such as the presence of anti-Ro/anti-La antibodies and the increased risk of neonatal lupus and congenital heart block $[13,17,27]$. Other studies indicated that anti-La antibodies were associated with developmental delays in offspring [26,28].

Animal studies demonstrated that anti-dsDNA antibodies and anti-NMDR antibodies, which are both present in SLE patients, cross the placenta and influence fetal neurological development [29]. Surprisingly, our study did not demonstrate a significant association between maternal SLE and long-term neurological morbidity. Lack of association might be due to the fact that some neurological-related morbidities only manifest at ages older than 18 years. Another explanation may be related to the fact that most women with SLE in our population did not manifest symptoms of severe disease during pregnancy and only a minority had positive autoantibodies such as anti-Ro/La of dsDNA autoantibodies. To understand the association between maternal SLE and its long-term neurological effects on offspring, further studies should be done to assess the neurodevelopment spectrum of offspring from childhood to adolescence and differences in offspring outcome between women with and without severe SLE during pregnancy.

\subsection{Strengths and Limitations of the Study}

Our study worked with a large population and with a long follow-up period, in an effort to evaluate the risk of neurologic-related hospitalizations in children born to mothers with SLE, thereby decreasing the chances of incorrect exposure and outcome data. By combining maternal, neonatal, and long-term childhood data, we were able to demonstrate the long-term outcomes of children, while controlling for several parameters during pregnancy and delivery. Healthcare in the country is universal, with all citizens provided equal and free medical care irrespective of their socio-economic standing. Inequity in medical access being reduced in such circumstances, it is unlikely that differences between social classes would be encountered. Nevertheless, our study has several limitations. First, our study lacked some clinical data regarding the severity of the disease, presence of specific antibodies and the treatment that was provided to mothers with SLE. However, as the two most common medications for treatment of SLE include antimalarial agents and corticosteroids, which have not been shown to effect long-term neurological development of the offspring, we would assume that the treatment provided to the mother would not influence the study's results [30-34]. In addition to this no data regarding the reasons for the preterm deliveries or the reasons for the perinatal mortality cases were known to us, Secondly, because our study was based on hospitalizations alone, our data include only severe neurological morbidities and exclude minor morbidities that are mainly treated in regional clinics. Another limitation of our study is the rareness of both the exposure (maternal SLE) and outcome (long- term neurological morbidity of the offspring) in our 
population, which may result in lack of power to demonstrate a positive correlation between the two. Finally, since patients can choose other places of health care, patients may have chosen to be treated in health centers other than SUMC

\section{Conclusions}

In conclusion, in our study population, maternal SLE does not appear to increase the risk for long-term neurologic hospitalizations in offspring. As most women with SLE during pregnancy in our population did not have severe disease during pregnancy and as the activity of the disease may influence the association between maternal SLE and longterm morbidity of the offspring, additional studies should investigate differences between mild to severe maternal SLE and their association with long- term neurological morbidity of the offspring. Further studies should also investigate the association between maternal SLE and other related neurodevelopmental concerns, in order to identify populations at need for long-term surveillance.

Supplementary Materials: The following are available online at https:/ /www.mdpi.com/article/10 .3390/jcm10132952/s1, Table S1: neurological morbidities ICD-9 codes.

Author Contributions: Conceptualization, D.D. and G.P.; methodology, T.W.; software, T.W.; validation, T.W.; formal analysis, T.W.; investigation, D.D. and G.P.; resources, G.P.; data curation, T.W.; writing—original draft preparation, D.D.; writing—review and editing, G.P., E.S., and S.M.; visualization, D.D.; supervision, G.P. and E.S.; project administration, G.P. All authors have read and agreed to the published version of the manuscript.

Funding: This research received no external funding.

Conflicts of Interest: The authors declare no conflict of interest.

\section{References}

1. Rahman, A.; Isenberg, D. Systemic Lupus Erythematosus. N. Engl. J. Med. 2008, 358, 929-939. [CrossRef]

2. Dörner, T.; Furie, R. Novel paradigms in systemic lupus erythematosus. Lancet 2019, 393, 2344-2358. [CrossRef]

3. Rees, F.; Doherty, M.; Grainge, M.; Lanyon, P.; Zhang, W. The worldwide incidence and prevalence of systemic lupus erythematosus: A systematic review of epidemiological studies. Rheumatology 2017, 56, 1945-1961. [CrossRef] [PubMed]

4. Wallace, D.J.; Gudsoorkar, V.S.; Weisman, M.H.; Venuturupalli, S.R. New insights into mechanisms of therapeutic effects of antimalarial agents in SLE. Nat. Rev. Rheumatol. 2012, 8, 522-533. [CrossRef]

5. Mohamed, A.; Chen, Y.; Wu, H.; Liao, J.; Cheng, B.; Lu, Q. Therapeutic advances in the treatment of SLE. Int. Immunopharmacol. 2019, 72, 218-223. [CrossRef]

6. Ruiz-Irastorza, G.; Khamashta, M. Lupus and pregnancy: Ten questions and some answers. Lupus 2008, 17, 416-420. [CrossRef] [PubMed]

7. Xu, J.; Chen, D.; Duan, X.; Li, L.; Tang, Y.; Peng, B. The association between antiphospholipid antibodies and late fetal loss: A systematic review and meta-analysis. Acta Obstet. Gynecol. Scand. 2019, 98, 1523-1533. [CrossRef]

8. Lockshin, M.D.; Kim, M.; Laskin, C.A.; Guerra, M.M.; Branch, D.W.; Merrill, J.T.; Petri, M.; Porter, T.F.; Sammaritano, L.R.; Stephenson, M.D.; et al. Prediction of adverse pregnancy outcome by the presence of lupus anticoagulant, but not anticardiolipin antibody, in patients with antiphospholipid antibodies. Arthritis Rheum. 2012, 64, 2311-2318. [CrossRef]

9. Singh, A.G.; Chowdhary, V.R. Pregnancy-related issues in women with systemic lupus erythematosus. Int. J. Rheum. Dis. 2014, 18, 172-181. [CrossRef] [PubMed]

10. Lateef, A.; Petri, M. Management of pregnancy in systemic lupus erythematosus. Nat. Rev. Rheumatol. 2012, 8, 710-718. [CrossRef]

11. Sammaritano, L.R. Management of Systemic Lupus Erythematosus during Pregnancy. Annu. Rev. Med. 2017, 68, 271-285. [CrossRef]

12. Bundhun, P.K.; Soogund, M.Z.S.; Huang, F. Impact of systemic lupus erythematosus on maternal and fetal outcomes following pregnancy: A meta-analysis of studies published between years 2001-2016. J. Autoimmun. 2017, 79, 17-27. [CrossRef] [PubMed]

13. Skog, A.; Tingström, J.; Salomonsson, S.; Sonesson, S.-E.; Wahren-Herlenius, M. Neurodevelopment in children with and without congenital heart block born to anti-Ro/SSA-positive mothers. Acta Paediatr. 2012, 102, 40-46. [CrossRef]

14. Vinet, É.; Pineau, C.A.; Clarke, A.E.; Scott, S.; Fombonne, E.; Joseph, L.; Platt, R.W.; Bernatsky, S. Increased Risk of Autism Spectrum Disorders in Children Born to Women with Systemic Lupus Erythematosus: Results from a Large Population-Based Cohort. Arthritis Rheumatol. 2015, 67, 3201-3208. [CrossRef]

15. Neri, F.; Chimini, L.; Bonomi, F.; Filippini, E.; Motta, M.; Faden, D.; Lojacono, A.; Rebaioli, C.B.; Frassi, M.; Danieli, E.; et al. Neuropsychological development of children born to patients with systemic lupus erythematosus. Lupus 2004, 13, 805-811. [CrossRef] [PubMed] 
16. Ross, G.; Sammaritano, L.; Nass, R.; Lockshin, M. Effects of Mothers' Autoimmune Disease during Pregnancy on Learning Disabilities and Hand Preference in Their Children. Arch. Pediatr. Adolesc. Med. 2003, 157, 397-402. [CrossRef] [PubMed]

17. Behan, W.M.H.; Behan, P.O.; Geschwind, N. Anti-Ro Antibody in Mothers of Dyslexic Children. Dev. Med. Child Neurol. 2008, 27, 538-540. [CrossRef]

18. Hirvonen, M.; Ojala, R.; Korhonen, P.; Haataja, P.; Eriksson, K.; Gissler, M.; Luukkaala, T.; Tammela, O. Cerebral Palsy Among Children Born Moderately and Late Preterm. Pediatrics 2014, 134, e1584-e1593. [CrossRef]

19. Freud, A.; Wainstock, T.; Sheiner, E.; Beloosesky, R.; Fischer, L.; Landau, D.; Walfisch, A. Maternal chorioamnionitis \& long term neurological morbidity in the offspring. Eur. J. Paediatr. Neurol. 2019, 23, 484-490. [CrossRef]

20. Central Bureau of Statistics. Israel in Figures, 2008-2017. [Updated 6 February 2019]. Available online: https://www.cbs.gov.il/ he/mediarelease/DocLib /2019/042/01_19_042b.pdf (accessed on 30 June 2021).

21. Pastore, D.E.A.; Costa, M.L.; Surita, F.G. Systemic lupus erythematosus and pregnancy: The challenge of improving antenatal care and outcomes. Lupus 2019, 28, 1417-1426. [CrossRef]

22. Fuchs, F.; Monet, B.; Ducruet, T.; Chaillet, N.; Audibert, F. Effect of maternal age on the risk of preterm birth: A large cohort study. PLoS ONE 2018, 13, e0191002. [CrossRef] [PubMed]

23. Heard, A.R.; Dekker, G.A.; Chan, A.; Jacobs, D.J.; Vreeburg, S.A.; Priest, K.R. Hypertension during pregnancy in South Australia, Part 1: Pregnancy outcomes. Aust. N. Z. J. Obstet. Gynaecol. 2004, 44, 404-409. [CrossRef]

24. Maducolil, M.K.; Al-Obaidly, S.; Olukade, T.; Salama, H.; AlQubaisi, M.; Al Rifai, H. Maternal characteristics and pregnancy outcomes of women with chronic hypertension: A population-based study. J. Périnat. Med. 2020, 48, 139-143. [CrossRef] [PubMed]

25. Urowitz, M.B.; Gladman, D.D.; MacKinnon, A.; Ibañez, D.; Bruto, V.; Rovet, J.; Silverman, E. Neurocognitive abnormalities in offspring of mothers with systemic lupus erythematosus. Lupus 2008, 17, 555-560. [CrossRef]

26. Nalli, C.; Iodice, A.; Andreoli, L.; Galli, J.; Lojacono, A.; Motta, M.; Fazzi, E.; Tincani, A. Long-term neurodevelopmental outcome of children born to prospectively followed pregnancies of women with systemic lupus erythematosus and/or antiphospholipid syndrome. Lupus 2017, 26, 552-558. [CrossRef] [PubMed]

27. Wahren-Herlenius, M.; Sonesson, S.-E. Specificity and effector mechanisms of autoantibodies in congenital heart block. Curr. Opin. Immunol. 2006, 18, 690-696. [CrossRef] [PubMed]

28. Marder, W.; Romero, V.C.; Ganser, M.A.; Hyzy, M.A.; Gordon, C.; McCune, W.J.; Somers, E.C. Increased usage of special educational services by children born to mothers with systemic lupus erythematosus and antiphospholipid antibodies. Lupus Sci. Med. 2014, 1, e000034. [CrossRef]

29. Wang, L.; Zhou, D.; Lee, J.; Niu, H.; Faust, T.W.; Frattini, S.; Kowal, C.; Huerta, P.; Volpe, B.T.; Diamond, B. Female mouse fetal loss mediated by maternal autoantibody. J. Exp. Med. 2012, 209, 1083-1089. [CrossRef] [PubMed]

30. Skuladottir, H.; Wilcox, A.; Ma, C.; Lammer, E.J.; Rasmussen, S.A.; Werler, M.M.; Shaw, G.M.; Carmichael, S.L. Corticosteroid use and risk of orofacial clefts. Birth Defects Res. Part A Clin. Mol. Teratol. 2014, 100, 499-506. [CrossRef] [PubMed]

31. Van Zutphen, A.R.; Bell, E.M.; Browne, M.L.; Lin, S.; Lin, A.E.; Druschel, C.M.; The National Birth Defects Prevention Study. Maternal asthma medication use during pregnancy and risk of congenital heart defects. Birth Defects Res. Part A Clin. Mol. Teratol. 2015, 103, 951-961. [CrossRef]

32. Clowse, M.E.B.; Magder, L.; Witter, F.; Petri, M. Hydroxychloroquine in lupus pregnancy. Arthritis Rheum. 2006, 54, 3640-3647. [CrossRef] [PubMed]

33. Cooper, W.O.; Cheetham, T.C.; Li, D.-K.; Stein, C.M.; Callahan, S.T.; Morgan, T.M.; Shintani, A.K.; Chen, N.; Griffin, M.R.; Ray, W.A. Brief report: Risk of adverse fetal outcomes associated with immunosuppressive medications for chronic immune-mediated diseases in pregnancy. Arthritis Rheumatol. 2013, 66, 444-450. [CrossRef] [PubMed]

34. Abarientos, C.; Sperber, K.; Shapiro, D.L.; Aronow, W.S.; Chao, C.P.; Ash, J.Y. Hydroxychloroquine in systemic lupus erythematosus and rheumatoid arthritis and its safety in pregnancy. Expert Opin. Drug Saf. 2011, 10, 705-714. [CrossRef] [PubMed] 